\title{
THE FIBRINOLYTIC ACTIVITY OF STREPTOKINASE ACTIVATED HUMAN PLASMIN ${ }^{1}$
}

\author{
BY SOL SHERRY \\ (From the May Institute for Medical Research of the Jewish Hospital Association, and De- \\ partment of Medicine, University of Cincinnati, College of Medicine, \\ Cincinnati, Ohio)
}

(Submitted for publication February 5, 1954; accepted March 22, 1954)

The successful introduction of enzymes for the dissolution of undesirable collections of sanguineous, fibrinous, and purulent exudations in localized areas of disease in man (1), has stimulated studies on the experimental in vivo dissolution of intravascular blood clots by enzymatic means (2-4). Activation of plasminogen, the proteolytic enzyme precursor present in plasma, to plasmin, by streptokinase ${ }^{2}$ has received considerable attention in these studies $(2,3,5)$ not only because of plasminogen's natural occurrence, but because of the special fibrinolytic propensities attributed to SK activated human plasmin $(6,7)$.

Preparations of the human proenzyme prepared by the Kline procedure ( 8 ) and activated by streptokinase, consistently have fibrinolytic activities of approximately 200,000 units per mg. nitrogen. ${ }^{3}$ The striking fibrinolytic activity of streptokinase activated human plasmin preparations is very large when compared to their known and measurable proteolytic activity. It seems unusual for an enzyme which extensively attacks a great variety of protein substrates (9-11), and has the same spectrum of activity as trypsin on synthetic substrates (12), to have such a unique fibrinolytic activity. It is the purpose of this report to present evidence that, (a) the fibrinolytic activity of human plasmin preparations is comparable to that of other known proteolytic enzymes, and (b) the extraordinary fibrinolytic activity of streptokinase activated human plasmin, when measured with the conventional bovine clot, is due to the activation of a contaminating bovine plasminogen in the fibrinogen preparation used in the assay system. This

1 This study was supported by a grant from the Lederle Laboratories Division, American Cyanamid Company.

2 Also referred to as SK.

8 An activity of this amount is represented by the ability of 0.005 gamma of plasmin $N$ to digest a standard fibrin clot in 30 minutes. contaminating plasminogen is rapidly activated by streptokinase in the presence of trace amounts of human plasminogen or plasmin. The activation of the bovine plasminogen, under these circumstances, results in abnormally high values for the fibrinolytic activity of human plasmin preparations. In general, the values obtained with the present fibrinolytic assay for streptokinase activated plasmin are approximately five hundred fold greater than the actual fibrinolytic activity of these human plasmin preparations.

The significance of these findings in relation to the diversity of data concerning the streptokinase activated plasma proteolytic system will be discussed.

\section{METHODS}

\section{Enzyme preparations:}

Human plasminogen. Prepared by the method of Kline (8). This procedure consistently yielded preparations of high activity.

Human plasmin. Three preparations of this enzyme were studied;

a) Human plasminogen activated by streptokinase, and referred to as streptokinase activated plasmin or SK plasmin.

b) A preparation of human plasmin derived from human plasminogen which spontaneously activated while human plasminogen was being reprecipitated three times during a three day period, according to the Kline procedure for plasminogen precipitation.

c) A spontaneously activated human plasmin preparation (Cohn's plasma Fraction IIIs), obtained through the courtesy of Dr. D. M. Surgenor, Harvard University Laboratory of Physical Chemistry.

Bovine plasminogen. Bovine plasma Fraction $\mathrm{III}_{2}$ or fresh plasma were used as sources of bovine plasminogen. Bovine plasmin (or bovine fibrinolysin). Obtained through the courtesy of Dr. E. Loomis, Parke, Davis and Co. This is a chloroform activated enzyme derived from bovine plasma (13).

4 Obtained through the courtesy of Dr. A. H. Holland, Jr. of Armour Laboratories. 
Other animal plasminogens. Fresh plasma was used as a source of dog plasminogen. Prothrombin free dried rabbit plasma (Difco) served as a rabbit plasminogen source.

Trypsin and Chymotrypsin (crystalline) (Worthington Labs.).

Streptokinase. A commercial preparation of Varidase (Lederle) (Lot No. 7-1089-287A) containing only small amounts of contaminating inhibitor. This preparation contained a number of other impurities including several non-proteolytic streptococcal enzymes. All references to unitage are in terms of Christensen units (14).

\section{Substrates:}

Bovine fibrinogen. Fraction I (Armour), an alcohol fraction of bovine plasma, was used in these studies. A number of different lots of this reagent were employed. Clots made with this preparation plus bovine thrombin 5 in the presence of various amounts of SK, were stable for 24 hours.

Plasminogen-deficient human fibrinogen. A sample of human fibrinogen obtained for study through the courtesy of Cutter Laboratories was further purified by three ammonium sulfate precipitations according to Laki's procedure (15). Although this preparation contained traces of human plasminogen, the contamination was not significant enough to influence the fibrinolytic assay. Clots produced with this reagent plus human ${ }^{6}$ or bovine thrombin, in the presence of SK, were stable for several hours. Furthermore, this human fibrinogen preparation was found to be relatively free of both plasmin inhibitor and antistreptokinase, and was suitable for use as a reagent in the fibrinolytic assay.

Casein. A preparation (Hammarsten quality) obtained from Nutritional Biochemicals.

TAMe. (p-toluenesulfonyl 1-arginine methyl ester). Synthesized in our laboratories by a modification of the method of Bergman, Fruton, and Pollok $(12,16)$.

LEe (1-lysine ethyl ester). Synthesized according to conventional methods (17).

Assays:

Fibrinolytic assay for streptokinase activated plasmin, spontaneously activated plasmin, and other proteolytic enzymes. The conventional assay utilizing a clot made with bovine reagents, according to the method of Christensen (14), was employed. When a clot made with human fibrinogen and thrombin was used, the procedure was similar to the Christensen method except for the substitution of human reagents in similar concentrations to the bovine reagents. In the fibrinolytic assay, the enzyme solution to be assayed is serially diluted with buffer, fol-

- The commercial bovine thrombin preparations of Upjohn and Parke, Davis and Co. were utilized. They contain approximately 25 N.I.H. clotting units per mg. material.

- A preparation obtained from Cutter Laboratories containing 20 N.I.H. clotting units per mg. material. lowed by the addition of fibrinogen and thrombin. ${ }^{7}$ When streptokinase was used as an activating agent for plasminogen, 1,000 units was incorporated into each of the assay tubes prior to the addition of thrombin. A fibrinolytic unit is defined as the smallest amount of enzyme which produces clot lysis in 30 minutes under the conditions of the test (14).

All reagents in this assay were made up in $0.025 \mathrm{M}$ phosphate buffer in 0.85 per cent sodium chloride at $\mathrm{pH}$ 7.5.8

Proteolytic assay. According to the casein assay of Remmert and Cohen (10). One casein unit is equivalent to the liberation of 450 gamma of acid soluble tyrosine under the conditions of the test.

$T A M e$ and $L E e$ esterase activity. According to the method previously described (12). The results are expressed as micromoles of acid liberated in 30 minutes at $37^{\circ} \mathrm{C}$. under the conditions of the test.

\section{RESULTS}

\section{The "unusual" fibrinolytic activity of $S K$ acti- vated human plasmin as compared to other plasmin preparations and trypsin}

In Table $I$ is shown a comparison of crystalline trypsin and several plasmin preparations, against three types of substrates which are attacked by both enzymes, i.e., casein, synthetic basic amino acid esters, and fibrin. The conventional assay of fibrinolytic activity was carried out with a bovine fibrinogen-bovine thrombin clot. Three types of plasmin preparations were assayed: a) an SK activated preparation, b) two spontaneously activated preparations, and c) a chloroform activated bovine plasmin.

From the data in Table I it will be noted that per milligram of nitrogen, trypsin, when compared to the most purified human plasmin preparations presently available, had 30 times as much proteolytic activity against casein, 140 fold the TAMe esterase activity, and 10 times the LEe esterase activity. However, the streptokinase activated human plasmin had a fibrinolytic activity 12 fold greater than trypsin, resulting in a fibrino-

${ }^{7}$ At the present state of purity of the reagents the action of trypsin and chymotrypsin appears to be greater on fibrinogen than fibrin, whereas the reverse is true with SK plasmin.

8 The presence of phosphate in the clotting mixture markedly accelerates plasmin fibrinolysis. Optimal acceleration was noted with $0.025 \mathrm{M}$ phosphate concentration. The effect of phosphate ion on fibrinolysis is being investigated. 
TABLE I

Comparison of the proteolytic, amino acid esterase, and fibrinolytic activity (bovine reagents) of several plasmin preparations, and trypsin

\begin{tabular}{|c|c|c|c|c|c|}
\hline \multirow[b]{2}{*}{ Enzyme } & \multirow{2}{*}{$\begin{array}{l}\text { Casein } \\
\text { units per } \\
m g . N\end{array}$} & \multicolumn{2}{|c|}{$\begin{array}{c}\text { Esterase activity } \\
\mu M \text { hyd. } / 30 \text { min. } / \text { mg. } N\end{array}$} & \multirow{2}{*}{$\begin{array}{c}\text { Fibrinolytic } \\
\text { assay } \\
\text { units per } \\
\text { mg. N } \\
\text { (Bovine clot) }\end{array}$} & \multirow{2}{*}{$\begin{array}{c}\text { Fibrinolytic } \\
\text { units per } \\
\text { casein } \\
\text { unit }\end{array}$} \\
\hline & & TAMe* & $\overline{\text { LEet }}$ & & \\
\hline $\begin{array}{l}\text { Trypsin } \\
\text { Plasmin, human }\end{array}$ & 2,015 & 107,000 & 5,000 & 14,900 & 7.4 \\
\hline $\begin{array}{l}\text { (Streptokinase activ. } \\
\text { human plasminogen) }\end{array}$ & 63 & 748 & 551 & 176,000 & 2,790 \\
\hline $\begin{array}{l}\text { Plasmin, human } \\
\text { (Spont. activated) } \\
\text { Plasmin, human } \mathrm{Fr} . \mathrm{III}_{3}\end{array}$ & 58 & 658 & 450 & 438 & 7.6 \\
\hline $\begin{array}{l}\text { (Spont. activated) } \\
\text { Plasmin, bovine }\end{array}$ & $\begin{array}{l}4.3 \\
1.0\end{array}$ & -25 & $\overline{10}$ & $\begin{array}{r}32 \\
8\end{array}$ & $\begin{array}{l}7.4 \\
8.0\end{array}$ \\
\hline
\end{tabular}

* p-toluenesulfonyl 1-arginine methyl ester.

$\uparrow$ 1-lysine ethyl ester.

lytic/proteolytic ratio 400 times greater than trypsin. This implies that per unit of proteolytic activity against casein, the streptokinase activated enzyme had a fibrinolytic activity 400 times that of trypsin. These differences in fibrinolytic activity, per proteolytic unit, entirely disappeared when streptokinase was not used as the activating agent. The spontaneously activated human enzymes, and the chloroform activated bovine plasmin had the same fibrinolytic activity per unit of proteolytic activity as trypsin.

\section{Lack of "unusual" fibrinolytic activity of $S K$ activated human plasmin when measured with a human clot}

The striking fibrinolytic activity of streptokinase activated human plasmin also disappeared when the fibrinolytic activity was assayed against a human fibrinogen-human thrombin clot rather than the usual bovine clot.

In Table II the fibrinolytic activity of crystalline trypsin, crystalline chymotrypsin, and several plasmin preparations as determined by assay with a clot made of human reagents, is compared to their proteolytic activity.

The data in Table II reveal that the streptokinase activated human plasmin, which had assayed at 176,000 fibrinolytic units/mg. $\mathrm{N}$. with the bovine reagents, had only 480 fibrinolytic units $/ \mathrm{mg}$. $\mathrm{N}$. when assayed against a standard clot composed of human reagents. Furthermore, the fibrinolytic activity per unit of proteolytic activity for the streptokinase activated plasmin was now closely comparable to that observed with the other plasmin preparations, trypsin and chymotrypsin.
The striking fibrinolytic activity of the SK activated human plasmin, as measured by the bovine clot assay, does not appear to be an accurate measure of the actual fibrinolytic activity of the SK plasmin preparation, and can be shown to be due to two phenomena: 1) streptokinase, in the presence of trace amounts of human plasminogen or plasmin, is an excellent activator for bovine and other animal plasminogens, and 2) bovine fibrinogen in the amounts used in the fibrinolytic assay is seriously contaminated with bovine plasminogen.

III. Activation of animal plasminogens by streptokinase in the presence of human plasminogen or plasmin

Figure 1 illustrates that streptokinase, in the presence of trace amounts of human plasminogen,

TABLE II

Comparison of the proteolytic and fibrinolytic activity (human reagents) of several plasmin preparations, trypsin, and chymotrypsin

\begin{tabular}{|c|c|c|c|}
\hline Enzyme & $\begin{array}{l}\text { Casein } \\
\text { units per } \\
\text { ms. } N\end{array}$ & $\begin{array}{c}\text { Fibrinolytic } \\
\text { assay } \\
\text { (human clot) } \\
\text { (units per } \\
\text { mg. p) }\end{array}$ & $\begin{array}{l}\text { Fibrinolytic } \\
\text { units per } \\
\text { casein } \\
\text { unit }\end{array}$ \\
\hline $\begin{array}{l}\text { Plasmin, human }{ }^{*} \\
\text { (SK activated } \\
\text { human plasminogen) }\end{array}$ & 63 & 480 & 7.6 \\
\hline $\begin{array}{l}\text { Plasmin, human } \\
\text { (Fraction III } \text { S }_{3} \\
\text { (Spont. activated) }\end{array}$ & 4.3 & 30 & 7.0 \\
\hline Plasmin, bovine & 1.0 & 7.5 & 7.5 \\
\hline Trypsin & 2,015 & 12,800 & 6.3 \\
\hline Chymotrypsin & 1,177 & 2,870 & 2.4 \\
\hline
\end{tabular}

* This preparation contained 176,000 fibrinolytic units per $\mathrm{mg}$. $\mathrm{N}$ when assayed with bovine reagents. 
A.

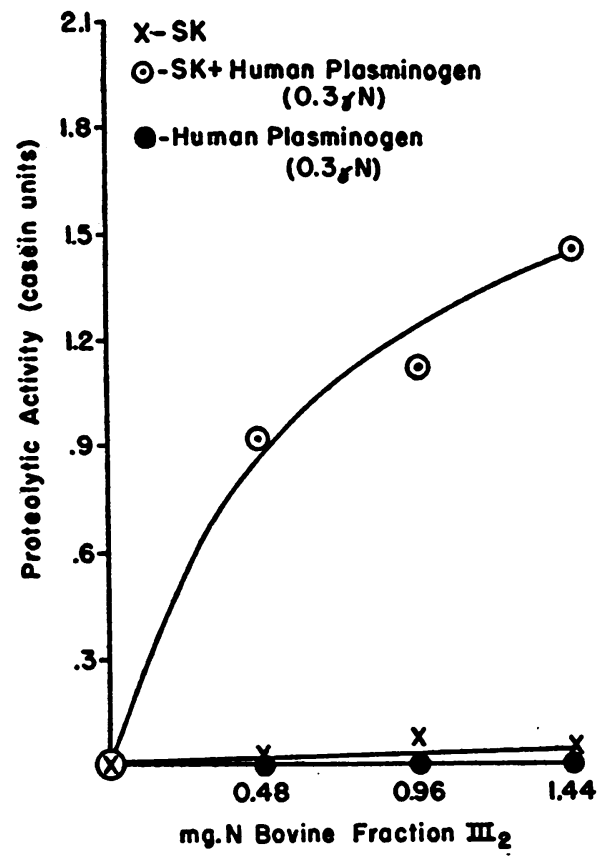

B.

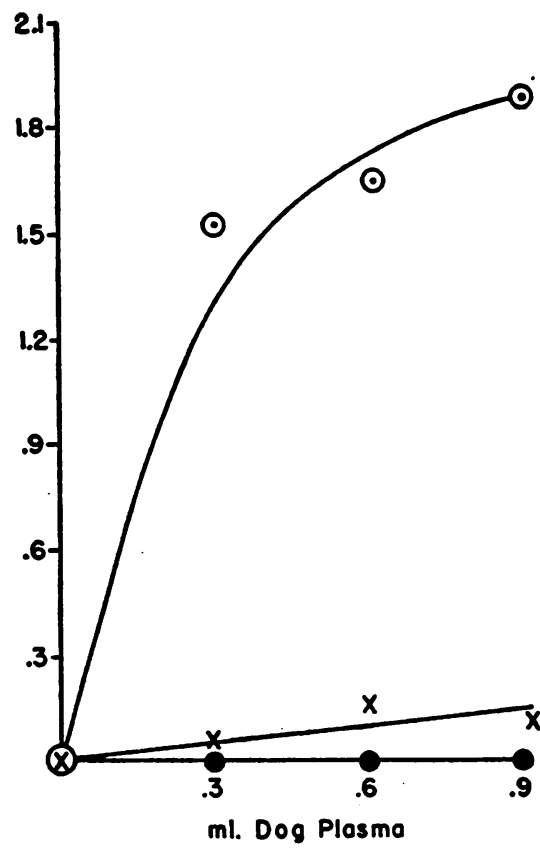

Fig. 1. Activation of Bovine and Dog Plasminogens by SK in the Presence op Human Plasminogen

Proteolytic activity formed measured by casein assay (ordinate). When SK was used, 1,000 units was added to test system.

A. Bovine System

Abscissa plots concentration of bovine fraction $\mathrm{III}_{2}$, used as source of bovine plasminogen in test mixture.

B. Dog System

Amounts of dog plasma, used as source of dog plasminogen, in test mixture is shown along abscissa.

is an excellent activator for both bovine and dog plasminogen, yet is without significant effect in the absence of the human factor.

For these experiments, bovine Fraction $\mathrm{III}_{2}$ was used as a source of bovine plasminogen (Figure 1A) while dog plasma was used as source of dog plasminogen (Figure 1B). Plasmin activity was measured by casein proteolysis. The human plasminogen employed was the highly purified preparation referred to in Table $I$ as having 63 casein units per $\mathrm{mg}$. $\mathrm{N}$ following SK activation. Note that only 0.3 gamma $N$ of this human plasminogen preparation was necessary to show this effect.

Similar observations on the activation of animal plasminogens have been made on : a) bovine plasma as the source of bovine plasminogen; $b$ ) dried rabbit plasma as the source of rabbit plasminogen; and c) in vivo in the dog following the intravenous in- jection of small amounts of human plasminogen mixed with SK (3).

The addition of bovine, dog or rabbit plasma, or of bovine Fraction $\mathrm{III}_{2}$ to a mixture of streptokinase and trace amounts of human plasmin, markedly accelerated the fibrinolysis of a standard human or bovine fibrinogen-thrombin clot.

The activation of these animal plasminogens by streptokinase was observed to occur either in the presence of human plasminogen or human plasmin. However, the presence of human plasminogen, or of human plasmin, alone, was without effect as an activator. The possible mechanism of this activation will be subsequently referred to in the discussion. It is probable that the human factor required in this activation is plasmin, or perhaps plasminogen, rather than some contaminant of the plasminogen preparations, since a) purification of human plasminogen or plasmin, of up to 300 fold, by a number of methods $(8,10,17,18)$ has resulted 
in a simultaneous purification of this activator function (12), b) in the presence of streptokinase, only minute traces of some of our purified plasminogen preparations (as little as 0.005 gamma $\mathrm{N}$ ) are necessary to show this effect, and c) inactivation of human plasminogen or plasmin by a variety of methods, results in a simultaneous loss of the activator function.

\section{Evidence that the bovine fibrinogen used in the fibrinolytic assay is contaminated with bovine plasminogen}

The data presented in Figure 2 illustrate that the bovine fibrinogen preparation usually employed in the fibrinolytic assay is seriously contaminated with bovine plasminogen.

In the experiment described in Figure 2A., the digestion of casein, by the bovine fibrinogen used in the fibrinolytic assay, was measured in the presence of streptokinase with and without trace amounts of human plasminogen ( 0.3 gamma $\mathrm{N})$. It will be seen that significant proteolysis was observed in the presence of the mixture of streptokinase plus trace amounts of human plasminogen, but not in the presence of plasminogen or streptokinase alone. These results indicate the activation of a proteolytic enzyme in the bovine fibrinogen preparation by the mixture of SK plus human plasminogen.

Figure 2B illustrates the effect of bovine fibrinogen, due to its bovine plasminogen contaminant, on fibrinolysis of a human clot. For this experiment, various amounts of bovine fibrinogen in 0.5 $\mathrm{ml}$. buffer were added to $0.5 \mathrm{ml}$. of 0.5 per cent human fibrinogen. One thousand units of streptokinase in $0.1 \mathrm{ml}$. were then added and the mixture clotted by the addition of 1 unit of human thrombin in $0.1 \mathrm{ml}$. buffer. The lysis time of the clots were then measured. The data in Figure 2B. reveal that significant fibrinolysis appeared with the incorporation of small amounts of bovine fibrinogen in the test system, and was progressively accelerated with increasing amounts of bovine fibrinogen. With the test system employed, a concentration of 0.25 per cent bovine fibrinogen, the amount used in the routine fibrinolytic assay, produced clot lysis in 12 minutes.

These observations have been confirmed on all
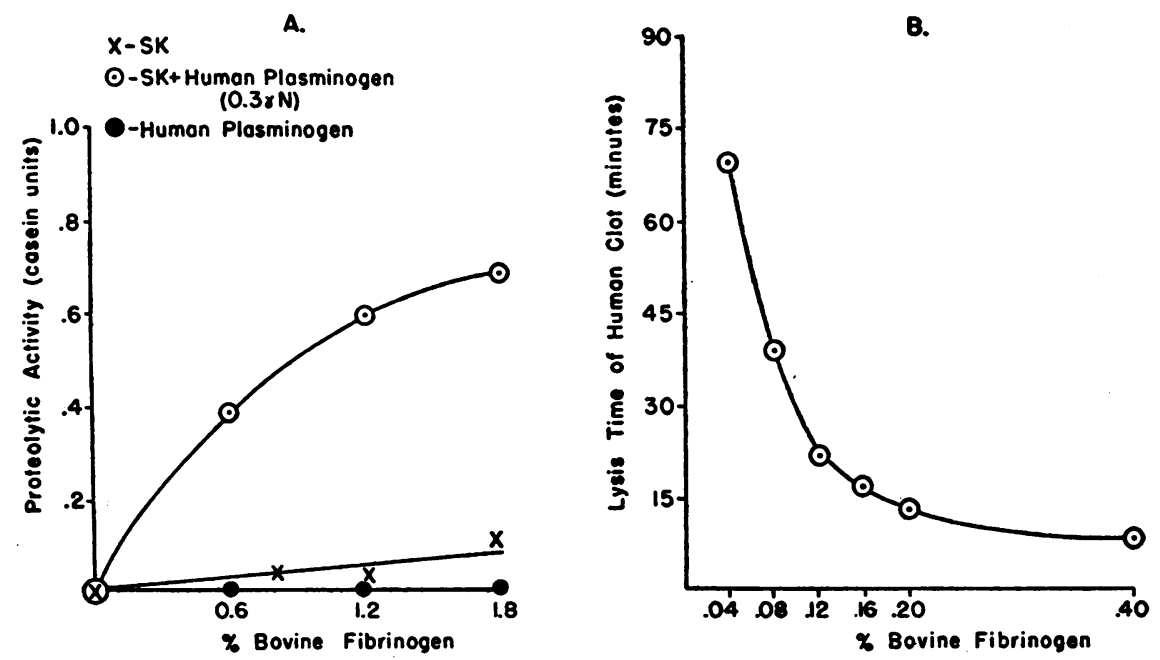

Fig. 2. A. Activation of a Protbolytic Enzymer in Bovine Fibrinogen Reacent by Streptokinase in the Presence of Human Plasminogen

Proteolytic activity found was measured by casein assay (ordinate). Abscissa plots concentration of bovine fibrinogen in test mixture. When SK used, 1,000 units was added to test system.

B. Accelnzation of Froprnotysis of a Human Clot by the Adpition of Bovine Fibrinogen to the Clotting Mixture

The ordinate plots the lysis time of the human clot in the presence of SK, and the abscissa the amount of bovine fibrinogen added to the clotting mixture. See text for details. 
of the lots of bovine fibrinogen tested. Although each lot differed somewhat quantitatively in the amount of bovine plasminogen present, they were qualitatively similar.

That these findings are attributable to a contamination of the fibrinogen with bovine plasminogen rather than associated with bovine fibrinogen itself was demonstrated, by studying the digestion of casein, or the acceleration of fibrinolysis, with the fluid expressed after the bovine fibrinogen was clotted with thrombin. Although some of the bovine plasminogen was adsorbed on the clot, sufficient amounts were present in the supernatant to confirm these observations. A number of attempts have been made to fractionate and concentrate the bovine plasminogen in the fibrinogen, by the procedure used for human plasminogen. The bovine plasminogen, however, appears to be much more labile, readily denaturing at acid $\mathrm{pH}$ 's. We are pursuing this phase of the investigation, however, in order to determine whether the bovine plasminogen has similar characteristics to the human enzyme.

Further evidence for the contamination of bovine fibrinogen with bovine plasminogen was obtained by purification of the bovine fibrinogen. When more highly purified bovine fibrinogen preparations were used as substrates in the fibrinolytic assay, there was a sharp reduction in the measurable fibrinolytic activity of streptokinase activated human plasmin. For this experiment two samples of bovine fibrinogen (Armours Fraction I, and a sample of fibrinogen obtained through the courtesy of Dr. Walter Seegers) were further purified by ammonium sulfate fractionation according to the technique described by Laki (15). A purified human plasminogen preparation ${ }^{\circ}$ was assayed for its streptokinase activatable fibrinolytic activity utilizing each of the four different fibrinogens at the same clottable protein concentration ( 0.15 per cent fibrinogen in the final clot). The fibrinolytic assay of the SK activated human plasmin with the original Armours Fraction I was 175,000 units per mg. N. With the purified Fraction I, the assay fell to 4,400 units per mg. N, or one-fortieth of the original assay. With the original Seegers fibrinogen, the SK activated human

\footnotetext{
- This preparation, following SK activation, had 60 casein units per mg. N.
}

plasmin specimen assayed at 350,000 units per $\mathrm{mg}$. $\mathrm{N}$. After purification of this fibrinogen, the SK plasmin assayed at only 820 units per mg. $\mathrm{N}$, or approximately one four-hundredth the original assay.

Plasminogen-deficient bovine fibrinogen could be readily prepared by subjecting the Armours Fraction I to a three-fold repurification according to the Laki technique (15). When this preparation was used as a substrate in the fibrinolytic assay, the assay of SK activated human plasmin was similar to that found with purified human fibrinogen.

The bovine thrombin preparations used in the fibrinolytic assay can also be readily demonstrated to contain bovine plasminogen. However, in the amounts used in the assay (1 thrombin unit) insignificant amounts of the contaminating plasminogen are added, and do not affect the assay. However, if ten or more units of thrombin are added to the clot, a significant effect on the assay becomes apparent.

\section{The influence of the bovine plasminogen con- taminant on the fibrinolytic assay for strepto- kinase activated plasmin}

It should be re-emphasized that the fibrinolytic assay for streptokinase activated plasmin is carried out by serially diluting the human proenzyme preparation and then adding an equal amount of bovine fibrinogen, SK and bovine thrombin to each of the assay tubes. Since the rapid activation of the bovine plasminogen contaminant of bovine fibrinogen requires only traces of human plasmin in the presence of SK, one would predict that while the addition of SK to a fully activated human plasmin preparation would not enhance the proteolytic activity, it should strikingly enhance the conventional fibrinolytic assay. In order to test this hypothesis, the spontaneously active human plasmin preparation, Fraction $\mathrm{III}_{8}$, was studied in the presence and absence of SK. This preparation had a spontaneous proteolytic activity of 4.3 casein units per mg. $\mathrm{N}$, which did not increase upon the addition of 1,000 units of streptokinase to each ml. of the enzyme preparation. However, the fibrinolytic assay of this preparation before the addition of SK was 32 units per mg. N, and was increased to 16,000 units per mg. $N$ following the ad- 


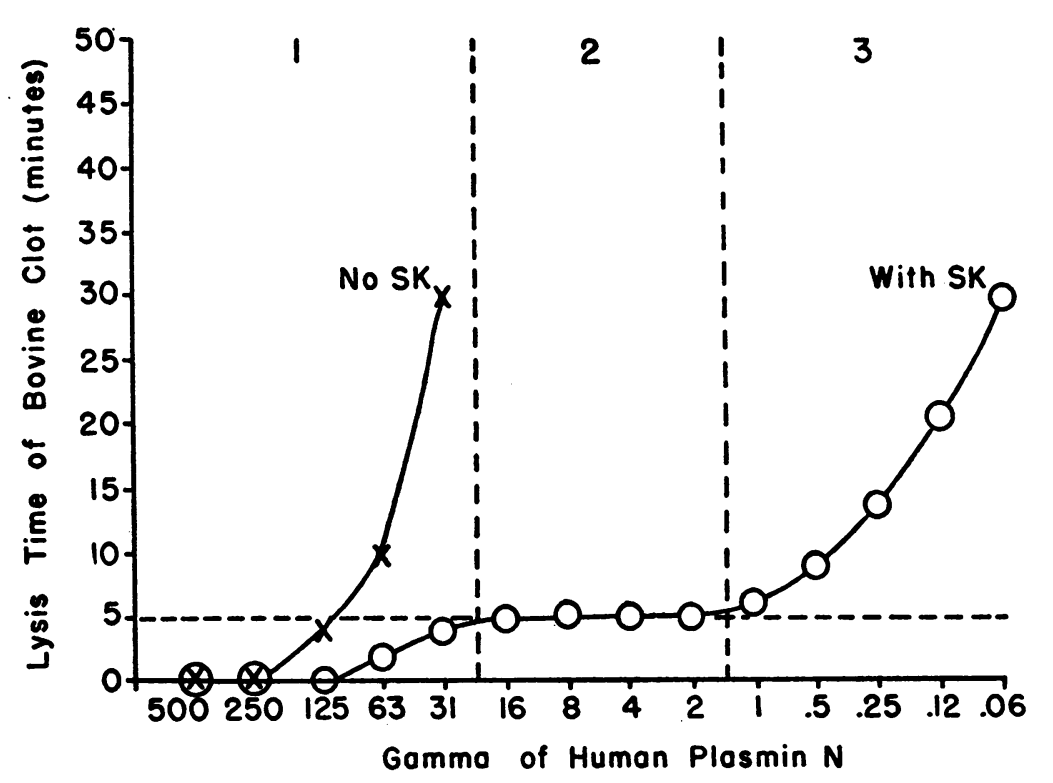

Fig. 3. Lysis Time of Bovine Clot as a Function of Human Plasmin Concentration (in the Presence and Absence of SK)

Note that the abscissa plots successive serial dilutions of human plasmin $\mathbf{N}$. See text for details.

dition of SK. The lysis times of the bovine clots with each serial dilution of the human plasmin preparation, in the presence and absence of SK, is shown in Figure 3.

Observations on the lysis time of the bovine clot, by the human plasmin preparation alone, revealed the expected relation of fibrinolysis time to enzyme concentration as seen with other proteolytic enzymes. Upon the addition of SK however, the pattern of fibrinolysis time to enzyme concentration was distinctly different. There was an initial zone where the lysis times were very rapid, but related to enzyme concentration; followed by a second zone where the lysis time was constant even though the human plasmin concentration was reduced 16-fold; followed by a third and final zone where concentration was again related to lysis time.

The kinetics of these observations on clot lysis may be explained by the presence of the contaminating bovine plasminogen in constant amounts in all the assay tubes, and its activation by the human plasmin plus SK. The horizontal broken line in Figure 3 may be interpreted as representing the lysis time of the clot which would result from the maximal activation of the contaminating bovine plasminogen present. The first zone represents the fibrinolytic activity of the activated bovine plasmin plus significant amounts of proteolytic activity derived from the human plasmin. In zone two, the amounts of human plasmin present do not significantly affect fibrinolysis, but are adequate, in the presence of SK, for complete activation of the bovine plasminogen. In zone three, the concentration of human plasmin has finally become a limiting factor in the activation of bovine plasminogen, resulting in a progressive prolongation of the clot lysis time as a function of human plasmin concentration.

Note that the activating function of human plasmin in the presence of SK, on bovine plasminogen, in this experiment, is 500 times the actual fibrinolytic activity of the human plasmin.

\section{Streptokinase as an essential component of the activating system}

Although not shown in Figure 3, and as would be expected, the lysis time of human clots, by various concentrations of the spontaneously activated human plasmin preparation Fraction $\mathrm{III}_{3}$, was not effected by the addition of 1,000 units of SK, and was similar to that observed for the bovine clots in the absence of SK. These latter observations suggest that human plasmin per se does not rapidly activate bovine plasminogen, and that SK 
is an essential component of the activating system. This was more effectively demonstrated by studying a preparation of purified human plasminogen which had ben activated to plasmin by SK; then inactivating the SK without destroying the plasmin; and finally adding fresh SK to restore that lost by the inactivating procedure. The inactivation of SK in the presence of purified human plasmin was accomplished by heating the preparation in a boiling water bath for 15 minutes at $\mathrm{pH}$ 2.0. Preliminary observations had shown that plasmin was stable at $\mathrm{pH} 2.0$ under these condition, ${ }^{10}$ whereas SK, in the presence of human plasmin, was fairly rapidly inactivated by this procedure.

A human plasminogen preparation containing $0.15 \mathrm{mg}$. N. per ml., and to which 17,000 units of SK had been added, was allowed to activate at room temperature for $\mathbf{1 0}$ minutes. Assay of the plasmin formed revealed 90,000 fibrinolytic units (bovine clot) and 28.9 casein units per mg. N. Following 15 minutes heating at $\mathrm{pH} 2.0$ in a boiling bath, the proteolytic assay of this preparation, when subsequently adjusted to the original $\mathrm{pH}$, was not significantly altered, but the fibrinolytic activity had fallen to 1,000 units per $\mathrm{mg}$. $\mathrm{N}$. Readdition of 17,000 units of fresh SK restored the fibrinolytic assay to its original 90,000 units per $\mathrm{mg}$. N. Since the fibrinolytic assay, under the conditions of the experiment cited, was primarily a measure of the activating function of the preparation studied, SK appears to be a necessary component of this activating system.

\section{DISCUSSION}

On the basis of the observations cited in this report, it appears that the fibrinolytic activity of human plasmin is comparable to that which has been demonstrated for a number of other proteolytic enzymes. In plasma, plasmin appears to attack fibrin more readily than fibrinogen but this may be due, as Ratnoff has suggested, to its ability to activate more readily in the presence of fibrin (19) or to local factors existing on a plasma clot. The data presented indicate that the fibrinolytic activity of plasmin, in a more purified system, is predictable on the basis of its general proteolytic properties. That the action of this enzyme in

10 True for purified plasmin preparations only, and not for plasma. plasma is not restricted to fibrinogen and fibrin is evident from the recent studies of Pillemer, Ratnoff, Blum, and Lepow on complement destruction (20), and of Ferguson, on the disappearance of Ac globulin (21).

It has recently been suggested that the intravenous injection of purified human plasminogen, which has been activated in vitro by SK, may prove useful as a clot dissolving agent in man (5). The basis for this view was the observation of significant circulating proteolytic and fibrinolytic activity following the injection of SK activated human plasmin into dogs. These observations however, have not taken into account, that this type of mixture activates the dogs plasminogen in vivo. We have used this procedure to activate the animals own plasminogen in vivo, and to evaluate plasmin as a clot dissolver (3). The injection of previously activated purified human plasminogen for clot dissolution in man, although deserving trial, may not be as promising as suspected, because of the low order of activity of the present preparations, as well as the obvious limitations on the amount of material available. However, since plasminogen is the naturally occurring proteolytic enzyme precursor of plasma, it would still appear that the in vivo activation of this enzyme in man, by the introduction of SK, may be the most desirable method for directly effecting the enzymatic dissolution of thrombi and emboli.

The observations described in this article reveal that the present assay using bovine fibrinogen and thrombin for the fibrinolytic activity of streptokinase activated human plasmin (14) is not a measure of the actual fibrinolytic activity of plasmin. This assay measures the activator function of human plasmin rather than its fibrinolytic activity. The activator function in the presence of SK can be measured with approximately $1 / 500$ of the amount of enzyme actually required to lyse a clot in thirty minutes. The measurement of the actual fibrinolytic activity of SK activated human plasmin requires more purified fibrinogen than those commercially available.

Similarly the present assay for streptokinase should be re-evaluated. The unit of streptokinase is defined as the smallest amount of SK, which in the presence of human plasminogen will produce lysis of a bovine clot in 10 minutes or less, and was conceived as representing the amount of 
kinase needed to rapidly activate sufficient human plasminogen to lyse a clot in the period noted (14). Our data suggest that the unit of SK may represent the amount of SK required in the presence of human plasminogen to rapidly activate the major portion of the bovine plasminogen contaminant present in the bovine reagents.

The observations reported on in this article are of some interest in relation to the recent literature concerning a) the mechanism of activation of plasminogen by streptokinase, b) the presence of a proactivator system in blood for plasminogen activation, and c) the participation of a complement-like factor in the streptokinase activation of human plasminogen:

Recently, the original studies of Christensen and MacLoed (22) on the kinase nature of activation of plasminogen by SK, have been seriously questioned (23). Wasserman, employing the fibrinolytic assay, showed that the kinetics of the activation of plasminogen by $\mathrm{SK}$, is compatible with the interpretation of a stoichiometric reaction, and that the formation of plasmin does not conform to the kinetics of an enzymatic reaction. The amount of plasmin formed, in the presence of an excess of plasminogen, was found to be dependent on the SK concentration, and that at all levels of streptokinase, maximal plasmin formation occurred almost instantaneously and did not increase with prolonged incubation.

Although we have been able to confirm Wasserman's observations, they may not yield information on the kinetics of human plasminogen activation by SK. In the fibrinolytic assay, these kinetics may be masked by the activation of the bovine plasminogen contaminating the reagents. Studies on the kinetics of plasminogen activation by streptokinase are also hampered by the impurities which are present in the available SK preparations. Preliminary data obtained with plasminogen-deficient fibrinogen are still in agreement with the initial observations of Wasserman, and suggest that the mechanism by which streptokinase activates human plasminogen may require further clarification.

The demonstration of bovine plasminogen activation by SK in the presence of human plasma, by Mullertz and Lassen (24) led him to hypothesize the presence of a proactivator in human plasma which was activated by SK, and that this activa- tor now converted human and all other animal plasminogens into plasmin. We are inclined to identify this activator function of human plasma, in the presence of SK, to human plasminogen or plasmin itself. This viewpoint is based on a) purification data $(12)$; b) the trace quantities of purified human plasminogen or plasmin preparations required; c) plasmin or plasminogen inactivation causing the loss of activator function; and d) inactivation of streptokinase, following its addition to human plasminogen or plasmin, results in an immediate loss of activator function; and is promptly restored by the addition of fresh SK.

The recent suggestion of Geiger that a complement-like factor participates in the activation of human plasminogen (25) was based on the marked increment of proteolytic activity which followed the addition of fresh animal sera to a mixture of SK and heated human globulin preparations. The heating of the human globulin was shown to inactivate most, but not all, of the human plasminogen. The observations cited in this report suggest that Geiger's results may be alternatively explained as a demonstration of the activation of the plasminogen of the various animal sera by the mixture of small amounts of human plasminogen and SK, without invoking the participation of another factor.

The mechanism for the activation of animal plasminogen by streptokinase in the presence of human plasminogen or plasmin is obscure. It can be shown that the presence of animal plasminogens does not enhance the ability of SK to activate human plasminogen. Our working hypothesis is that the plasma inhibitor to the activation of the various animal plasminogens by streptokinase has a much greater affinity for human plasminogen or plasmin than it does for its respective plasminogen. The addition of the human factor results in a release of the animal plasminogen for activation by streptokinase. An alternative view, also under exploration, is that the rapid activation of plasminogen is carried out by a SK-plasmin complex, and that human plasmin combines more readily with $\mathrm{SK}$ in this respect than the plasmin of other animals.

\section{SUMMARY}

1. The ratio of fibrinolytic to proteolytic activity of human plasmin, in more purified systems, 
is of the same order as that shown by trypsin and chymotrypsin.

2. Streptokinase, in the presence of minute amounts of human plasminogen or human plasmin, activates the bovine plasminogen contaminating the bovine fibrinogen in the fibrinolytic assay.

3. The fibrinolytic assay for streptokinase activated human plasmin, as presently employed with bovine fibrinogen and thrombin, measures the activator function of the human enzyme rather than the fibrinolytic activity of the human plasmin.

\section{ACKNOWLEDGMENT}

The author acknowledges with gratitude the many excellent suggestions of Dr. Walter Troll, and the technical assistance of Miss Mary E. Schmidt in this study.

\section{REFERENCES}

1. Tillett, W. S., and Sherry, S., The effect in patients of streptococcal fibrinolysin (streptokinase) and streptococcal desoxyribonuclease on fibrinous, purulent, and sanguineous pleural exudations. J. Clin. Invest., 1949, 28, 173.

2. Johnson, A. J., and Tillett, W. S., The lysis in rabbits of intravascular blood clots by the streptococcal fibrinolytic system (streptokinase). J. Exper. Med., 1952, 95, 449.

3. Sherry, S., Titchener, A., Gottesman, L., Wasserman, P., and Troll, W., The enzymatic dissolution of intravascular clots. J. Lab. \& Clin. Med., 1953, 42, 952 (Abst.).

4. Innerfield, I., Schwarz, A., and Angrist, A., Intravenous trypsin: its anticoagulant, fibrinolytic, and thrombolytic effects. J. Clin. Invest., 1952, 31, 1049.

5. Cliffton, E. E., Cannamela, D. A., and Grossi, C., In vivo studies of human plasmin. Intravenous injection in dogs and rabbits. J. Applied Physiol., 1953, 6, 143.

6. Biggs, R., and MacFarlane, R. G., Human Blood Coagulation and Its Disorders. Springfield, IIl., Charles C Thomas, 1953.

7. Cliffton, E. C., and Cannamela, D. A., Fibrinolytic and proteolytic activity of a human 'plasminogen,' prepared from fraction III of human plasma. J. Applied Physiol., 1953, 6, 42.

8. Kline, D. L., The purification and crystallization of plasminogen (profibrinolysin). J. Biol. Chem., 1953, $204,949$.

9. Christensen, L. R., Streptococcal fibrinolysis: A proteolytic reaction due to a serum enzyme activated by streptococcal fibrinolysin. J. Gen. Physiol., $1945,28,363$.
10. Remmert, LeM., and Cohen, P. P., Partial purification and properties of a proteolytic enzyme of human serum. J. Biol. Chem., 1949, 181, 431.

11. Todd, E. W., Quantitative studies on the total plasmin and the trypsin inhibitor of human blood serum. I. Methods for the titration of total plasmin and of trypsin inhibitor. J. Exper. Med., 1949, 89, 295.

12. Troll, W., Sherry, S., and Wachman, J., The action of plasmin on synthetic substrates. J. Biol. Chem., 1954, 208, 85.

13. Loomis, E. C., George, C., Jr., and Ryder, A., Fibrinolysin: Nomenclature, unit, assay, preparation and properties. Arch. Biochem., 1947, $12,1$.

14. Christensen, L. R., Methods for measuring the activity of components of the streptococcal fibrinolytic system, and streptococcal desoxyribonuclease. J. Clin. Invest., 1949, 28, 163.

15. Laki, K., The transition of fibrinogen to fibrin in Blood Clotting and Allied Problems, Transactions of the Fourth Conference, 1951, ed. by J. E. Flynn, Josiah Macy, Jr. Foundation, New York, 1951, p. 217.

16. Bergmann, M., Fruton, J. S., and Pollok, H., The specificity of trypsin. J. Biol. Chem., 1939, 127, 643.

17. Christensen, L. R., and Smith, D. H., Jr., Plasminogen purification by acid extraction. Proc. Soc. Exper. Biol. \& Med., 1950, 74, 840.

18. Milstone, H., A factor in normal human blood which participates in streptococcal fibrinolysis. J. Immunol., 1941, 42, 109.

19. Ratnoff, O. D., Studies on a proteolytic enzyme in human plasma. IX. Fibrinogen and fibrin as substrates for the proteolytic enzyme of plasma. J. Clin. Invest., 1953, 32, 473.

20. Pillemer, L., Ratnoff, O. D., Blum, L., and Lepow, I. H., The inactivation of complement and its components by plasmin. J. Exper. Med., 1953, $97,573$.

21. Ferguson, J. H., in Flynn, J. E., and Standley, E. T., On the conversion of prothrombin to thrombin in Blood Clotting and Allied Problems, Transactions of the Second Conference, 1949, ed. by J. E. Flynn, Josiah Macy, Jr. Foundation, New York, 1949, p. 174.

22. Christensen, L. R., and MacLoed, C. M., A proteolytic enzyme of serum: Characterization, activation, and reaction with inhibitors. J. Gen. Physiol., 1945, 28, 559.

23. Wasserman, A. E., Streptokinase activation of a proteolytic enzyme in human blood. Arch. Biochem. \& Biophys., 1952, 41, 158.

24. Mullertz, S., and Lassen, M., An activator system in blood indispensable for formation of plasmin by streptokinase. Proc. Soc. Exper. Biol. \& Med., 1953, 82, 264.

25. Geiger, W. B., Involvement of a complement-like factor in the activation of blood protease. J. Immunol., 1952, 69, 597. 